\title{
Bringing Europe together through primary care
}

At the end of August 2015, the European Forum for Primary Care (EFPC) held its 10th conference in Amsterdam. This represented a significant moment in the history of the EFPC and for Primary Health Care Research and Development $(P H C R D)$. The conference brought together primary care researchers, practitioners and decision makers from across all parts of Europe as well as participants from the United States and Canada.

The theme of the conference was 'Integrated Primary Care: Research, Policy \& Practice'. The keynote presentations and additional sessions represented a range of European and international perspectives on this theme and can be viewed on the EFPC website (http://www.euprimarycare. org/amsterdam/efpc-2015-amsterdam-conference30-august-1-september). Notably, the conference was well represented from a multi-disciplinary perspective with primary care participants including nurses, midwives, occupational health practitioners, physiotherapy, pharmacy as well as GPs and others. This in itself provides a very positive message about a European position on integration of primary care services in order to provide a more systematic and effective service for our communities.

The Editors in Chief of PHCRD were honoured to announce that the journal is now formally affiliated with EFPC. This means that members of EFPC will be able to access the journal online, contribute to the editorial board, author new papers, propose and edit special issues and publish their position papers in the journal. This is a really positive step for the journal and for EFPC as we will be able to disseminate research and development activities that uphold our shared values and aims in the light of the wider global goals of primary care. The main aim of the EFPC is:

'to improve the health of the population by promoting strong Primary Care. This is done by advocating for Primary Care, by generating data and evidence on Primary Care and by exchanging information between its members'. (http://www.euprimarycare.org/)
We believe that $P H C R D$ can play a pro-active and significant part in supporting EFPC to meet this aim, and that by publishing position papers and research and development studies the work of EFPC will be extended to networks and organisations outside of Europe.

PHCRD has a long history of publishing papers on issues that concern primary care researchers and practitioners across Europe. These papers reflect ongoing and new challenges, for example, those presented by the sustainable development goals (SDGs) approved by the United Nations in September 2015. Ongoing challenges concerning management of long-term conditions, interdisciplinary working, mental health and recording systems to name but a few topics of concern to primary care, have all been addressed over the years in many papers in the journal. More recent challenges, for example, concerning austerity have also been considered by Simou et al.'s (2015) discussion of primary care in Greece. The paper by van den Muijsenbergh et al. (2014) that reports on the RESTORE project both illustrates the long-standing awareness in primary care of the needs of migrants with different cultural and language backgrounds and the importance of cross-European studies in understanding and addressing their needs. The SDGs (Le Blanc, 2015) for 2030 will now take the world beyond the Millennium Development Goals that were set for 2015. The SDGs are broad and ambitious with an overarching aim to eradicate poverty, the most known detrimental determinant of health. Other goals include 'Attain Healthy Living for All' and 'End hunger, improve nutrition and promote sustainable agriculture'. On first reading, the SDGs are vast and far-reaching and present wide spread challenges for primary care research and practice. The relevance of the SDGs may be seen in stark relief against the rising numbers of refugees across Europe and the challenges this movement presents for primary care across the continent. During the EFPC conference, Jan de Maeseneer raised the challenge of refugees in Europe as an issue for primary care to address. A range of proposals were put forward and presented by Kate O'Donnell 
(http://www.euprimarycare.org/sites/default/files/ EFPC_Refugees_and_Primary_Care.pdf), they all demonstrate commitment to the values of primary care and the contribution that can be made to achieving the SDGs.

A European community facing the realities of mass migration and refugees seeking asylum brings new horizons for primary health care and for integration into different cultural norms. In upholding the values of primary care, practitioners, researchers and decision makers have to start somewhere in order to make the difference that a community orientated, first point of access health-care system can contribute to health outcomes of people across the globe. Integration of care, working in partnership between people, sectors and professions, putting the whole person at the centre of care are at the heart of what primary care can offer. By role modelling these values and demonstrating through robust evidence that primary care works pluralistically as well as within its local or national frameworks, there is the real potential for primary care to contribute to the SDGs by 2030 . Organisations such as EFPC and journals such as $P H C R D$ are natural repositories and outlets for researching, analysing, describing and disseminating the evidence for what primary care can offer by working at local, regional and national levels. This accumulation of data, the integration of larger data sets for the potential for meta-analysis in demonstrating the outcomes and gaps in primary care are concrete ways in which scientific organisations and journals can work in partnership towards achieving the higher level goals.

The Editors in Chief are looking forward to a new phase in the journal's development working alongside the EFPC, bringing a culturally pluralistic European perspective to our publication through partnership and integration.

\section{Sally Kendall and Rosamund Bryar Editor in Chief}

\section{References}

Le Blanc, D. 2015: Towards integration at last? The sustainable development goals as a network of targets. UN DESA Working Paper No. 141, UN, Geneva.

Simou, E., Karamagioli, E. and Roumeliotou, A. 2015: Reinventing primary health care in the Greece of austerity: the role of health-care workers. Primary Health Care Research \& Development 16, 5-13.

van den Muijsenbergh, M., van Weel-Baumgarten, E., Burns, N., O'Donnell, C., Mair, F., Spiegel, W., Lionis, C., Dowrick, C., O'Reilly-de Brún, M., de Brun, T., MacFarlane, A. 2014: Communication in cross-cultural consultations in primary care in Europe: the case for improvement. The rationale for the RESTORE FP 7 project. Primary Health Care Research \& Development 15, 122-33. 